\title{
Intra-Seasonal Oscillation (ISO) of south Kerala rainfall during the summer monsoons of 1901-1995
}

\author{
P V Joseph*, Anu Simon, Venu G Nair and Aype Thomas \\ Department of Atmospheric Sciences, Cochin University of Science and Technology, Fine Arts Avenue, \\ Cochin 682016 , India. \\ *e-mail: porathur@md4.vsnl.net.in
}

\begin{abstract}
Time series of daily averaged rainfall of about 40 rain gauge stations of south Kerala, situated at the southern-most part of peninsular India between latitudes about $8^{\circ} \mathrm{N}$ and $10^{\circ} \mathrm{N}$ were subjected to Wavelet Analysis to study the Intra Seasonal Oscillation (ISO) in the rainfall and its interannual variability. Of the 128 days, 29th May to 3rd October of each of the 95 years 1901-1995 were analysed. We find that the period of ISO does not vary during a monsoon season in most of the years, but it has large inter-annual variability in the range 23 to 64 days. Period-wise, the years cluster into two groups of ISO, the SHORT consisting of periods 23, 27 and 32 days and the LONG with a single period of 64 days, both the sets at a significance level of $99 \%$. During the 95 years at this level of significance there are 44 years with SHORT and 20 years with LONG periods. 11 years have no ISO even at the $90 \%$ level of significance.

We composited NCEP SST anomalies of the summer monsoon season June to September for two groups of years during the period 1965-1993. The first group is of 5 years with a LONG ISO period of 64 days for south Kerala rainfall at significance level of $99 \%$ and the second group is of 12 years with SHORT ISO periods of 23,27 and 32 days at the same level of significance. The SST anomaly for the LONG (SHORT) ISO resembles that for an El Nino (La Nina).
\end{abstract}

\section{Introduction}

The economy of India with its large population is closely linked with the performance of the summer monsoon. Delayed/early arrival and abnormal fluctuations in the summer monsoon rainfall cause severe strain. Understanding these fluctuations therefore assumes great importance. Since Kerala is the gateway of the summer monsoon to India (Joseph et al 1994), a thorough investigation of the monsoon over Kerala will be very useful. Moreover, south Kerala being in the low latitude belt $\left(8^{\circ} \mathrm{N}-10^{\circ} \mathrm{N}\right)$, low frequency modes like Madden Julian oscillation affect it throughout the year and east-west oriented maximum cloud zones (Sikka and Gadgil 1980) form at 30-50 day intervals to its south and move north across it during the May to October period.
It is well known that Indian summer monsoon exhibits prominent low frequency intra-seasonal oscillation of periods $30-50$ days and 10 to 20 days (Krishnamurti 1985). The 30 to 50 day oscillation in monsoon is associated with variability in large scale circulation and convection features in the tropical atmosphere. The equatorial 30 to 50 day oscillation was first detected by Madden and Julian (1971, 1972) in zonal wind and convection. Eastward propagating large scale features on 30 to 50 day time scale have been studied by Lorenc (1984) in velocity potential, and by Weickmann (1983), Weickmann et al (1985), Lau and Chan $(1985,1986)$ and Murakami et al (1986) in Outgoing Longwave Radiation (OLR).

Although the Active-Break cycle of the monsoon with a periodicity in this range was known for almost a hundred years, details of the 30-

Keywords. Intra Seasonal Oscillation (ISO); El Nino and La Nina; SST anomalies; DRY and WET monsoons; SHORT and LONG period ISO; wavelet analysis.

Proc. Indian Acad. Sci. (Earth Planet. Sci.), 113, No. 2, June 2004, pp. 139-150

(C) Printed in India. 
50 day monsoon oscillation were captured only after weather satellite data became available for routine use. Yasunari $(1979,1980,1981)$ and Sikka and Gadgil (1980) reported convective cloud bands moving northward across India and southeast Asia on this time scale. Krishnamurthi and Subramanyam (1982) studied the 30 to 50 day mode in wind field anomalies at $850 \mathrm{hPa}$ of the 1979 summer monsoon using MONEX data. Their study showed zonal troughs and ridges with 3 to $6 \mathrm{~m} / \mathrm{s}$ wind anomalies propagating steadily from the equator to the Himalayas. The zonal extent of this anomalous area is about 60 degrees in longitude. This low frequency mode has been viewed as a seesaw in convective cloudiness between the equatorial Indian Ocean and the monsoon trough region or as a northward movement of an east-west oriented band of convective clouds from low latitudes of Indian Ocean to the Himalayas. Analysis of a 70year (1901-70) record of daily rainfall of 3700 stations of India by Hartmann and Michelson (1989) revealed a strong spectral peak at 40-50 day time scale over India south of $23^{\circ} \mathrm{N}$. Lau and Chan (1986) showed that for the period May to October variance of the OLR was strong in the tropical Indian and west Pacific Oceans in the period range 40 to 50 days and that there was a see-saw between Indian and west Pacific Oceans in OLR (convection). Wang and Rui (1990) and Rui and Wang (1990) studied cases of large scale (spatial) negative anomalies in OLR (areas of active convection) moving eastwards across the Indian and Pacific Oceans in the equatorial belt. The convection anomalies develop over equatorial Africa, intensify over the Indian Ocean, weaken over the maritime continent and intensify again over western Pacific and then move east. They weaken again around the date line. Northward motion was observed over the Indian and west Pacific Oceans during the period May to October.

From the beginning it was clear that this oscillation hereafter called Intra Seasonal Oscillation (ISO), had a highly variable period. Madden and Julian (1994) in their review of the work done on the ISO discovered by them two decades earlier, concluded that the periods of ISO varied from year to year and ranged from 22 to 79 days and that ISO was prominent in nearly 75 per cent of the years. Their conclusions were however, based on studies using short periods of data.

A question of importance is whether the period of ISO during the boreal summer monsoon season has any dependence on the occurrence of $\mathrm{El}$ Nino/La Nina, the strength of Indian summer monsoon etc. Yasunari (1980) observed that the period of ISO increased to nearly 60 days during the summer of 1972 a severe drought year for India (and also a strong El Nino year). On the other hand,
Madden and Julian (1994) showed evidence from literature, a shift to lower periods during El Nino southern oscillation events. Please also see Gray (1988) and Kuhnel (1989). More recently Lawrence and Webster (2001) have examined the dependence of monsoon ISO activity on the Indian summer monsoon strength and east Pacific SST anomalies (El Nino/La Nina) using a short data set (1975 to 1997) and found that the ISO period is essentially independent of ENSO or Indian monsoon strength.

We have studied the monsoon ISO in the period range 20-100 days in the daily averaged southwest monsoon rainfall of south Kerala for ninetyfive years (1901 to 1995). This is the longest record studied so far. Singh et al (1992) had examined one degree square average daily monsoon rainfall of India of 80 years (1901-1980) for inter-annual variability of the period of ISO and found that there are two groups of periods, one 30-60 days and the other 8-30 days. Their study points out that the intensity of these oscillations are not related to the monsoon or the El Nino southern oscillation. Chowdhury et al (1988) found that 30 to 60 day period is the prominent ISO over central India. The variance explained by the 10-20 day ISO exceeds that of the 30-60 day ISO in good monsoon years.

Section 2 discusses the data used in this study. For studying the ISO of south Kerala rainfall we have used the Wavelet Analysis method. Since it is a relatively new technique we have given details of the method used in Appendix 1. ISO of south Kerala monsoon rainfall in the period range 20 to 100 days of the 95 years 1901-1995 is discussed in section 3. We have two groups of periods at the level of significance of $99 \%$ : one LONG with a period of 64 days and the other SHORT, which comprises of periods 23,27 and 32 days. Section 4 is about the relationship between the ISO period and rainfall of south Kerala during the monsoon season. Relation between the ISO period and some large-scale features of the atmosphere and ocean is the topic of section 5. Case studies of two years with ISO of periods 64 and 32 days are discussed in section 6. Summary of the main findings of the study is given in section 7 .

\section{Data and method of analysis}

The rain gauge network of Kerala whose data for the period 1901-1980 was used in this study is shown in figure 1. The dividing latitude between south and north Kerala is about $10^{\circ}$ N. South Kerala has 44 rain gauge stations with long records of rainfall. Ananthakrishnan and Soman (1988) using the data of daily rainfall at these stations 


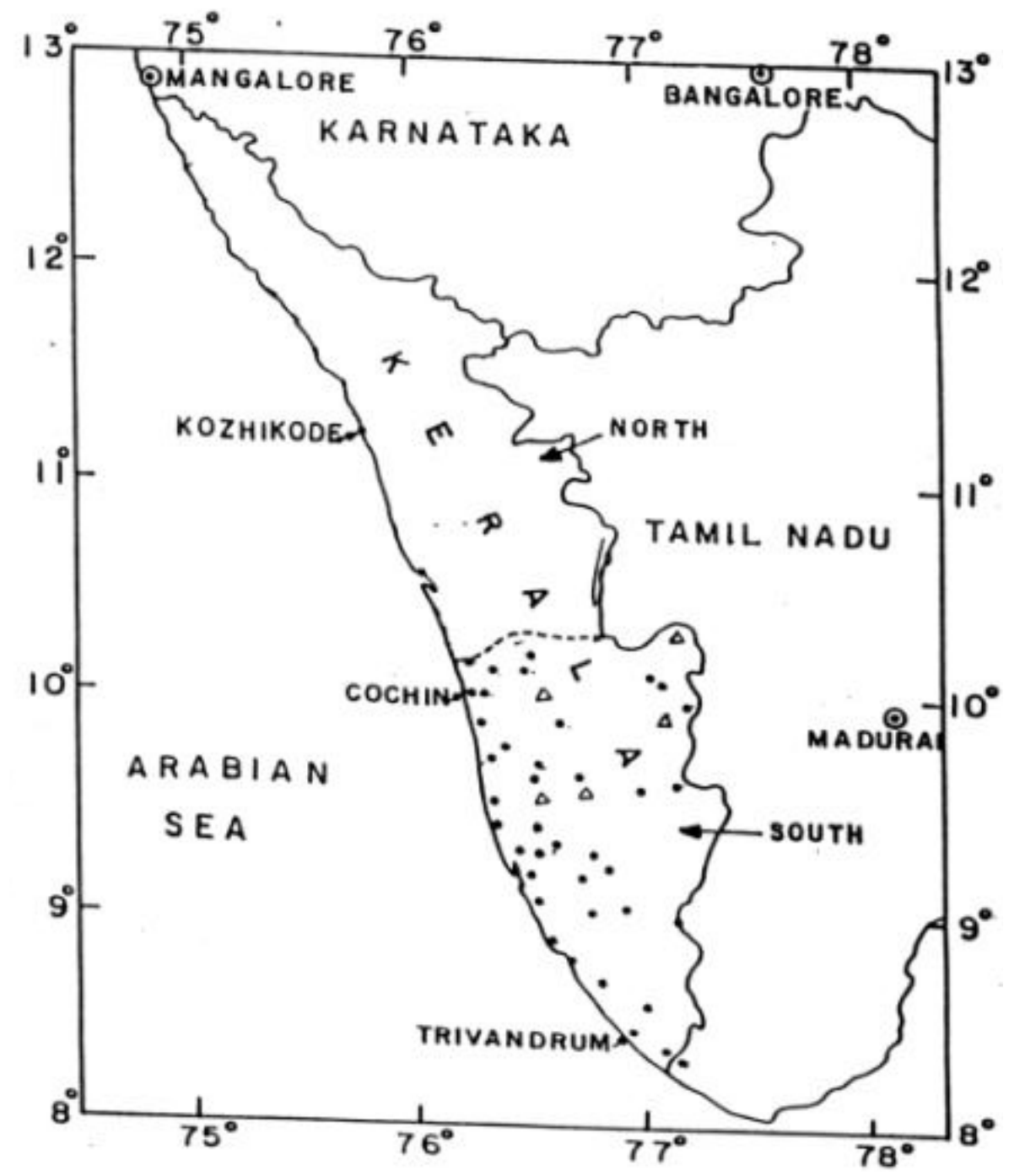

Figure 1. Rainguage network of south Kerala (marked by dots) whose data are used in this study for 1901 to 1995 . Stations not included in the time series 1981 to 1995 are marked by triangles.

constructed daily rainfall series for south Kerala by averaging the rainfall at individual stations. This data set for 80 years (1901 to 1980) donated to Cochin University of Science \& Technology by Dr. Soman (a few months before his sad and untimely death) is the basic data for this study. For the period 1981-1995, an average of 39 stations in south Kerala has been used (figure 1). The five stations whose data are not used for the period 19811995 are marked by triangles. Daily rainfall series of south Kerala of length 128 days (29th May to 3rd October) of 95 years (1901 to 1995) are used in this study. We examined the problem of whether taking 39 stations instead of 44 stations for calculating mean rainfall of south Kerala for the later period 1981 to 1995 will cause any discontinuity in the analysis at year 1980. Even with half the number of stations (20 stations) randomly chosen the resulting time series show no change in the period of ISO.
SST data used in the study is as given along with the NCEP/NCAR data analysis of Kalnay et al (1996) and it is on a nearly $1.9 \times 1.9$ degree latitudelongitude grid. SST data from the UK Met office are used up to 1988 after which SST from Reynolds (CPC) are used. Since there is a strong trend in SST we have calculated SST anomalies for each month removing a 11-year running mean to get a monthly data series for 1965-1993. This data set is hereafter called the NCEP SST data.

To analyse for the periodicities contained in the time series of south Kerala rainfall, we made use of wavelet transform method. It is an analysis tool well suited to study multiscale, non-stationary processes occurring over finite spatial and temporal domain. Since its introduction by Morlet (1983), this technique has found wide application in diverse fields. Wavelet analysis gives the localised variations of power within a time scale by decomposing a time series in time-frequency space 
and one is able to determine both the dominant modes of variability and how those modes vary in time. The details of this technique are given in Appendix 1.

The technique of wavelet transform was used to study ISO in rainfall of south Kerala of periods in the range 20 to 100 days. The resolved periods correspond to $23,27,32,38,45,54,64,76$, and 91 days. Since the total time series length is only 128 days we have omitted periods longer than half the length of the series, that is periods of 76 and 91 days.

\section{ISO of south Kerala rainfall}

For south Kerala the prominent periodicities in the monsoon season's daily rainfall were picked up from Wavelet Analysis for significance levels 90\%, 95\% and 99\%. Each year of the period 1901-1995 had at least one period which could thus be picked up, except for 11 years having no significant period. These years are 1920, 1929, 1937, 1945, 1959, 1968, 1969, 1980, 1984, 1985 and 1990. The periods of the ISO for each significance level (90\%, $95 \%$ and $99 \%$ ) are given in table 1 . There are many years having more than one period. The frequency distribution of the periods significant at $90 \%, 95 \%$ and $99 \%$ are given in table 2 .

There are two main clusters for the periods. One cluster is the period range 23 days to 45 days with maximum frequency in the range of periods 23 days to 32 days and the other cluster is of a single period of 64 days. Close to 64 day periods the period 54 days has zero cases. Out of the 25 cases of 64 day periods, 20 are significant at $99 \%$ level. The cluster of periods 23, 27 and 32 days is called SHORT and the cluster with a single period of 64 days is called LONG in this study. We have studied the properties of these two clusters of periods LONG and SHORT. In table 2 we see that for significance level of $99 \%$, SHORT and LONG period ISO are found in 44 and 20 years respectively out of the 95 years 1901 to 1995 .

\section{ISO period and south Kerala's monsoon rainfall}

The long period mean of south Kerala rainfall is $176.5 \mathrm{~cm}$ and its standard deviation is $36 \mathrm{~cm}$. DRY (WET) years are taken as years with south Kerala rainfall one standard deviation below (above) the long term mean. Out of the 15 DRY monsoon years during 1901-1995, nine years have LONG and 2 years SHORT ISO. Out of 16 WET monsoon years in the same 95 years, 5 years have LONG ISO and 6 years have SHORT ISO (only ISO periods at the $99 \%$ level of significance have been considered). DRY and WET years are marked in table 1 as Dr and We respectively. Thus LONG period has a preference for DRY years in south Kerala rainfall.

\section{ISO period and large scale features of sea surface temperature}

We have composited NCEP SST anomalies of the summer monsoon season June to September for two groups of years during 1965-1993. The first group is of 5 years with LONG ISO period of 64 days for south Kerala rainfall at a significance level of $99 \%$ and the second group is of 12 years with SHORT ISO periods of 23, 27 and 32 days at the same level of significance. These years and the corresponding ISO periods of south Kerala rainfall are given in table 3 .

Figures 2(a) and 2(b) give the SST anomaly composites of the monsoon season, June to September for LONG and SHORT period composites respectively. It is seen that for the LONG period composite there is a large area of positive SST anomaly in the equatorial central and east Pacific Ocean. Weaker positive and negative anomalies are seen over the Indian Ocean and western Pacific Ocean respectively. The SST anomaly signals over the Indian and Pacific Oceans are similar to the composite El Nino anomaly of Rasmusson and Carpenter (1982) and Tourre and White $(1995,1997)$. The SST anomaly composite for the SHORT periods is similar to typical La Nina case. Thus we conclude that the low frequency mode in south Kerala rainfall has periods that are related to the largescale SST anomalies in the tropical areas of Indian and Pacific Oceans. We examined SST anomalies of the individual years of the LONG and SHORT composites. In the LONG composite one individual year out of 5 (1973) did not agree with the composite SST pattern and in the SHORT two years out of the 12 (1976 and 1983) did not agree.

\section{Case studies of SHORT and LONG ISO}

A study of 95 years of south-west monsoon rainfall of south Kerala has shown that its daily rainfall of the period June to September has strong and significant ISO in most of the years. Although the period of oscillation remains nearly the same throughout a season, there is a pronounced interannual variability in the periods. The analysis has brought out a prominent period of 64 days, which appears in a very large number of years either as the only period or in combination with lower period oscillations. Case studies of one LONG and one SHORT period ISO of south Kerala rainfall are presented here. 
Table 1. Significant periods of south Kerala monsoon rainfall during 1901-1995, El Nino, La Nina, WET and DRY monsoon years are indicated against the years by EI, LA, Dr and We.

\begin{tabular}{|c|c|c|c|c|c|c|c|c|c|c|c|c|c|c|c|}
\hline & Year & & Period & & & Year & & & iod & & Year & & & & \\
\hline & 1901 & $27^{* *}$ & $32^{*}$ & & & 1936 & & $32^{*}$ & $38^{*}$ & & 1971 & & $32^{* *}$ & $27^{*}$ & \\
\hline $\mathrm{El}$ & 1902 & $64^{* *}$ & & & & 1937 & & & & & 1972 & Dr & $27^{*}$ & $32^{*}$ & 64 \\
\hline $\mathrm{La}$ & 1903 & $23^{* *}$ & $27^{*}$ & 32 & $38 \quad 45$ & 1938 & & $23^{* *}$ & $27^{* *}$ & & 1973 & & $64^{* *}$ & & \\
\hline & 1904 & 27 & & & & 1939 & & $27^{* *}$ & $32^{* *}$ & & 1974 & & $23^{* *}$ & & \\
\hline $\mathrm{El}$ & 1905 & 27 & & & & 1940 & & 32 & & & 1975 & & $27^{* *}$ & $32^{*}$ & \\
\hline $\mathrm{La}$ & 1906 & $32^{*}$ & & & & 1941 & & $27^{*}$ & $32^{*}$ & 23 & 1976 & Dr & $32^{* *}$ & $27^{*}$ & \\
\hline $\mathrm{El}$ & 1907 & $23^{* *}$ & $64^{* *}$ & & & 1942 & & 32 & & & 1977 & Dr & $45^{* *}$ & $38^{*}$ & \\
\hline La & 1908 & $38^{*}$ & 45 & & & 1943 & & $38^{* *}$ & $45^{* *}$ & & 1978 & & 32 & & \\
\hline & 1909 & $45^{* *}$ & $38^{*}$ & & & 1944 & Dr & $23^{* *}$ & $27^{* *}$ & & 1979 & Dr & $23^{*}$ & 64 & \\
\hline & 1910 & $27^{* *}$ & & $32^{*}$ & & 1945 & & & & & 1980 & & & & \\
\hline $\mathrm{El}$ & 1911 & 38 & 45 & & & 1946 & We & $64^{* *}$ & & & 1981 & & $32^{* *}$ & $27^{*}$ & \\
\hline & 1912 & 32 & & & & 1947 & We & $32^{* *}$ & & & 1982 & Dr & $64^{* *}$ & 23 & \\
\hline & 1913 & $45^{*}$ & & & & 1948 & & $64^{* *}$ & & & 1983 & & $32^{* *}$ & & \\
\hline $\mathrm{El}$ & 1914 & $23^{*}$ & $27^{*}$ & & & 1949 & & $23^{* *}$ & $45^{*}$ & & 1984 & & & & \\
\hline & 1915 & $32^{* *}$ & $27^{*}$ & & & 1950 & & $45^{* *}$ & $38^{*}$ & & 1985 & Dr & & & \\
\hline $\mathrm{La}$ & 1916 & $45^{* *}$ & $38^{*}$ & & & 1951 & & & & & 1986 & Dr & $45^{*}$ & 23 & 38 \\
\hline & 1917 & $23^{* *}$ & $27^{* *}$ & $32^{*}$ & & 1952 & Dr & $64^{* *}$ & & & 1987 & Dr & $64^{* *}$ & & \\
\hline $\mathrm{El}$ & 1918 & $64^{* *}$ & & & & 1953 & & $23^{* *}$ & $27^{* *}$ & & 1988 & & $23^{* *}$ & & \\
\hline & 1919 & $64^{* *}$ & & & & 1954 & & $23^{* *}$ & $27^{* *}$ & & 1989 & & $32^{* *}$ & 27 & \\
\hline $\mathrm{La}$ & 1920 & & & & & 1955 & & $32^{*}$ & & & 1990 & Dr & & & \\
\hline & 1921 & $64^{*}$ & & 45 & & 1956 & & $64^{* *}$ & $23^{*}$ & & 1991 & We & $64^{* *}$ & & \\
\hline & 1922 & $64^{*}$ & & & & 1957 & & $27^{* *}$ & & & 1992 & We & $23^{* *}$ & $27^{* *}$ & \\
\hline $\mathrm{El}$ & 1923 & $38^{*}$ & $64^{*}$ & 45 & & 1958 & & $64^{* *}$ & 27 & & 1993 & & $27^{*}$ & & \\
\hline $\mathrm{La}$ & 1924 & 23 & 38 & 45 & & 1959 & We & & & & 1994 & & $45^{* *}$ & $38^{*}$ & \\
\hline $\mathrm{El}$ & 1925 & $23^{* *}$ & $27^{*}$ & & & 1960 & & $23^{* *}$ & 27 & & 1995 & & $23^{* *}$ & $27^{* *}$ & \\
\hline & 1926 & $45^{*}$ & 38 & & & 1961 & We & $23^{* *}$ & $27^{*}$ & & & & & & \\
\hline & 1927 & $23^{* *}$ & $27^{*}$ & & & 1962 & & $64^{* *}$ & 32 & & & & & & \\
\hline $\mathrm{La}$ & 1928 & $27^{* *}$ & $23^{*}$ & & & 1963 & & $23^{* *}$ & $27^{* *}$ & & & & & & \\
\hline & 1929 & & & & & 1964 & & $32^{* *}$ & & & & & & & \\
\hline $\mathrm{El}$ & 1930 & $38^{* *}$ & $45^{* *}$ & & & 1965 & Dr & $64^{* *}$ & & & & & & & \\
\hline $\mathrm{La}$ & 1931 & $64^{* *}$ & & & & 1966 & & $27^{* *}$ & $23^{*}$ & & & & & & \\
\hline $\mathrm{El}$ & 1932 & $64^{* *}$ & & & & 1967 & & $23^{* *}$ & 27 & & & & & & \\
\hline & 1933 & $64^{* *}$ & $23^{*}$ & & & 1968 & We & & & & & & & & \\
\hline & 1934 & $64^{* *}$ & & & & 1969 & & & & & & & & & \\
\hline & 1935 & $64^{* *}$ & $23^{*}$ & & & 1970 & & $27^{* *}$ & $32^{* *}$ & & & & & & \\
\hline
\end{tabular}

Significance levels (by chi-square test) at $99 \%, 95 \%$ and $90 \%$ are denoted by suffixes ${ }^{* *, *}$ and no suffix respectively. 
Table 2. Frequency distribution of periods of south Kerala monsoon rainfall in the range 20-100 days at different significance levels 99\%, 95\% and 90\% during the period 1901-1995.

\begin{tabular}{ccccr}
\hline & \multicolumn{4}{c}{ Number of years at significance levels } \\
Period & $99 \%$ & $95 \%$ & $90 \%$ & Total \\
\hline 64 & 20 & 3 & 2 & 25 \\
54 & 0 & 0 & 0 & 0 \\
45 & 7 & 4 & 6 & 17 \\
38 & 2 & 8 & 5 & 15 \\
32 & 10 & 9 & 7 & 26 \\
27 & 16 & 12 & 6 & 34 \\
23 & 18 & 7 & 4 & 29 \\
\hline
\end{tabular}

Table 3. SHORT (23-32 days) and LONG (64 days) period ISO at significance 99\% during 1965 to 1993 of south Kerala monsoon rainfall. Other ISO periods present are also marked.

\begin{tabular}{|c|c|c|c|c|}
\hline \multirow{2}{*}{$\begin{array}{c}\text { LONG years } \\
1965\end{array}$} & ISO periods & \multirow{2}{*}{$\begin{array}{c}\text { SHORT years } \\
1966\end{array}$} & \multicolumn{2}{|c|}{ ISO periods } \\
\hline & $64^{* *}$ & & $27^{* *}$ & $23^{*}$ \\
\hline 1973 & $64^{* *}$ & 1967 & $23^{* *}$ & 27 \\
\hline 1982 & $64^{* *} \quad 23$ & 1970 & $27^{* *}$ & $32^{* *}$ \\
\hline 1987 & $64^{* *}$ & 1971 & $32^{* *}$ & $27^{*}$ \\
\hline \multirow[t]{8}{*}{1991} & $64^{* *}$ & 1974 & $23^{* *}$ & \\
\hline & & 1975 & $27^{* *}$ & $32^{* *}$ \\
\hline & & 1976 & $32^{* *}$ & $27^{*}$ \\
\hline & & 1981 & $32^{* *}$ & $27^{*}$ \\
\hline & & 1983 & $32^{* *}$ & \\
\hline & & 1988 & $23^{* *}$ & \\
\hline & & 1989 & $32^{* *}$ & 27 \\
\hline & & 1992 & $23^{* *}$ & $27^{* *}$ \\
\hline
\end{tabular}

\subsection{7 - a case of LONG ISO of period 64 days}

Figure 3(a) gives the daily rainfall of south Kerala and its seven-day moving average. Monsoon rainfall has occurred in two spells separated by about two months. There are long periods of very low rainfall. Wavelet Analysis of daily rainfall shows a 64-day period significant at 99\% level (figure 3b) Other years like 1982, 1965, 1958 and 1918 etc., showing significant 64-day ISO signal at $99 \%$ level also show long dry spells in the daily rainfall of south Kerala (figures not given).

Figure 5(a) gives the NCEP SST anomaly of monsoon season of 1987. Equatorial central and east Pacific Ocean had large areas covered by warm
SST anomalies. 1987 was an El Nino year. South Kerala had a dry monsoon in 1987. As against the long term average south Kerala monsoon season rainfall of $176.5 \mathrm{~cm}, 1987$ monsoon gave only $111 \mathrm{~cm}$.

\subsection{9 - a case of SHORT ISO of period 32 days}

Figure 4(a) gives the daily rainfall of south Kerala and its seven day moving average for the year 1989. Wavelet Analysis of south Kerala rainfall is shown in figure 4(b). The ISO period here is 32 days significant at $99 \%$ level. Dry spells in south Kerala had a very short duration in 1989 unlike in 1987. Figure 5(b) gives the NCEP SST anomaly of monsoon season of 1989. Equatorial central Pacific Ocean and Indian Ocean had large areas covered by cold SST anomalies like in a La Nina. South Kerala had normal rainfall during 1989 and received $149 \mathrm{~cm}$ of rainfall during the south-west monsoon season.

\section{Summary}

Time series of mean daily rainfall of south Kerala using data from a network of 39 to 44 rain gauge stations for the summer monsoon season of 95 years (1901-1995) have been analysed to study the inter-annual variation of the period of the intraseasonal oscillations in rainfall. Each data series has 128 days of daily rainfall data from 29th May to 3rd October. Intra Seasonal Oscillations (ISO) of periods $23,27,32,38,45,54$, and 64 days were resolved using Wavelet Analysis and their statistical significance at levels $90 \%, 95 \%$ and $99 \%$ were determined.

It is found that out of the 95 years, 11 years had no significant ISO. Period-wise the remaining years clustered into two groups, the SHORT of periods 23, 27 and 32 days and the LONG with a single period of 64 days. At the $99 \%$ level of significance SHORT and LONG period ISO were found in 44 and 20 years. Composites of LONG (SHORT) period ISO significant at $99 \%$ of the years 1965 to 1993 showed that the SST anomalies are of the El Nino (La Nina) type in the tropical Pacific and Indian Oceans.

\section{Acknowledgements}

The authors thank the Cochin University of Science and Technology and its Department of Atmospheric Sciences for providing facilities for work particularly its Data Bank and Computer Division. 
త

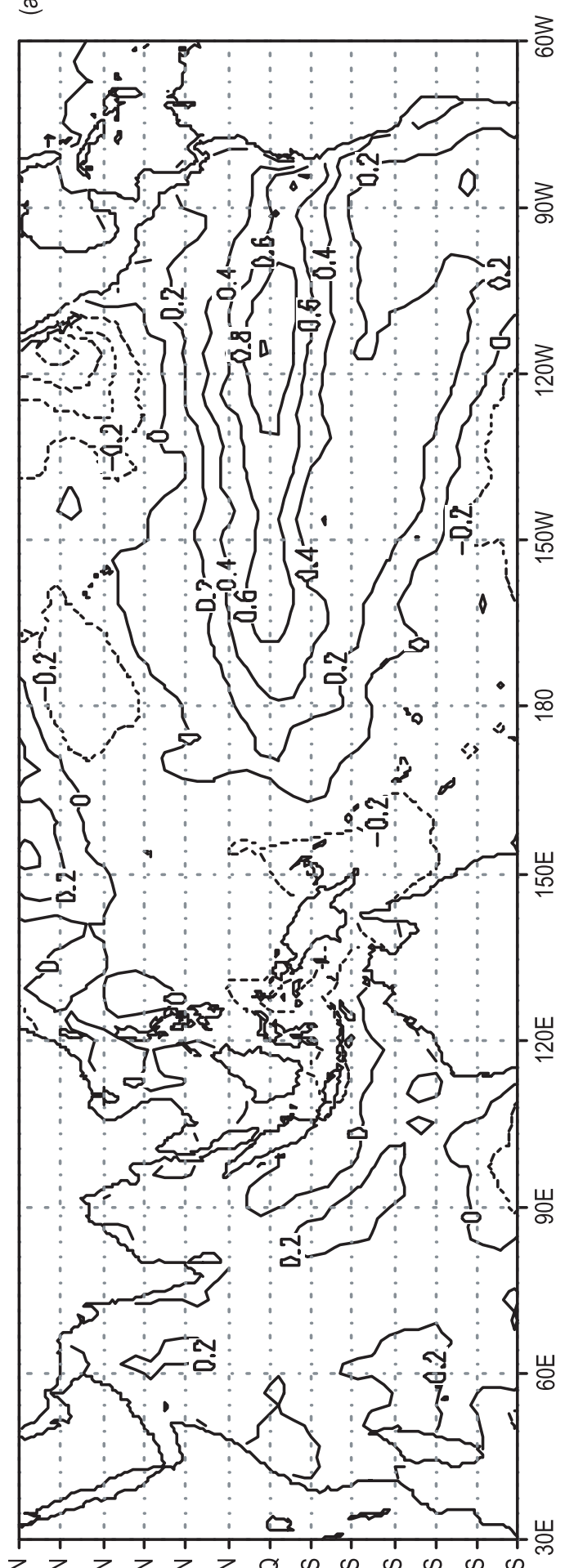

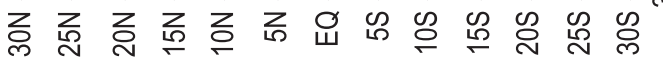

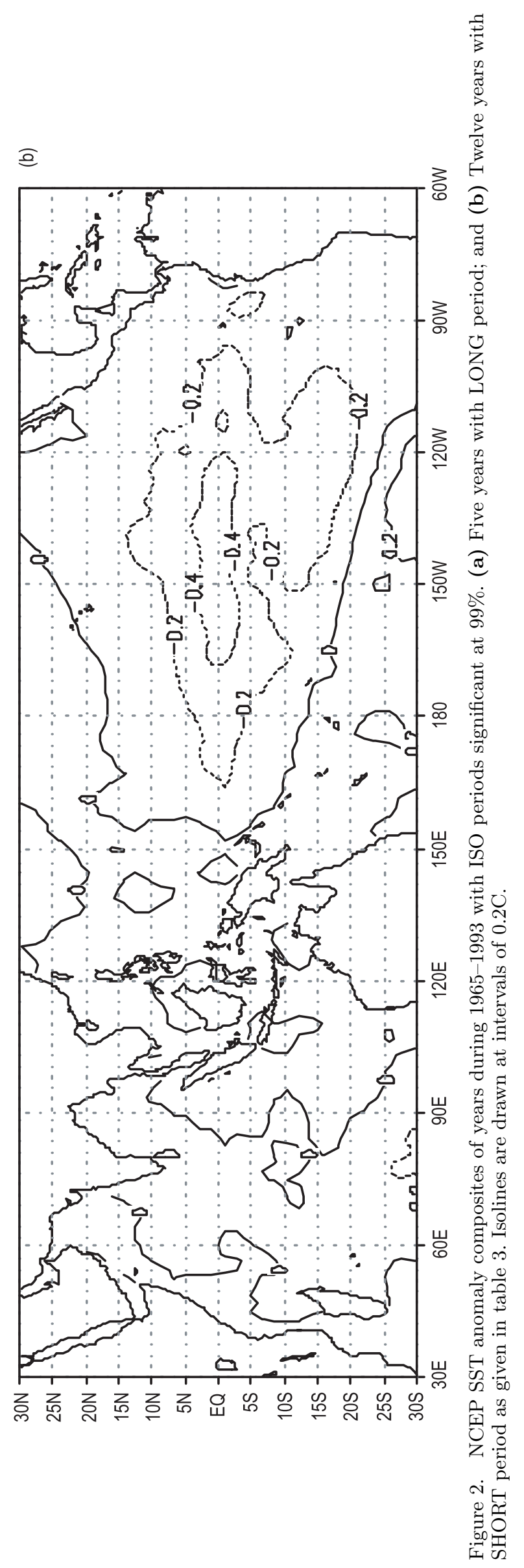




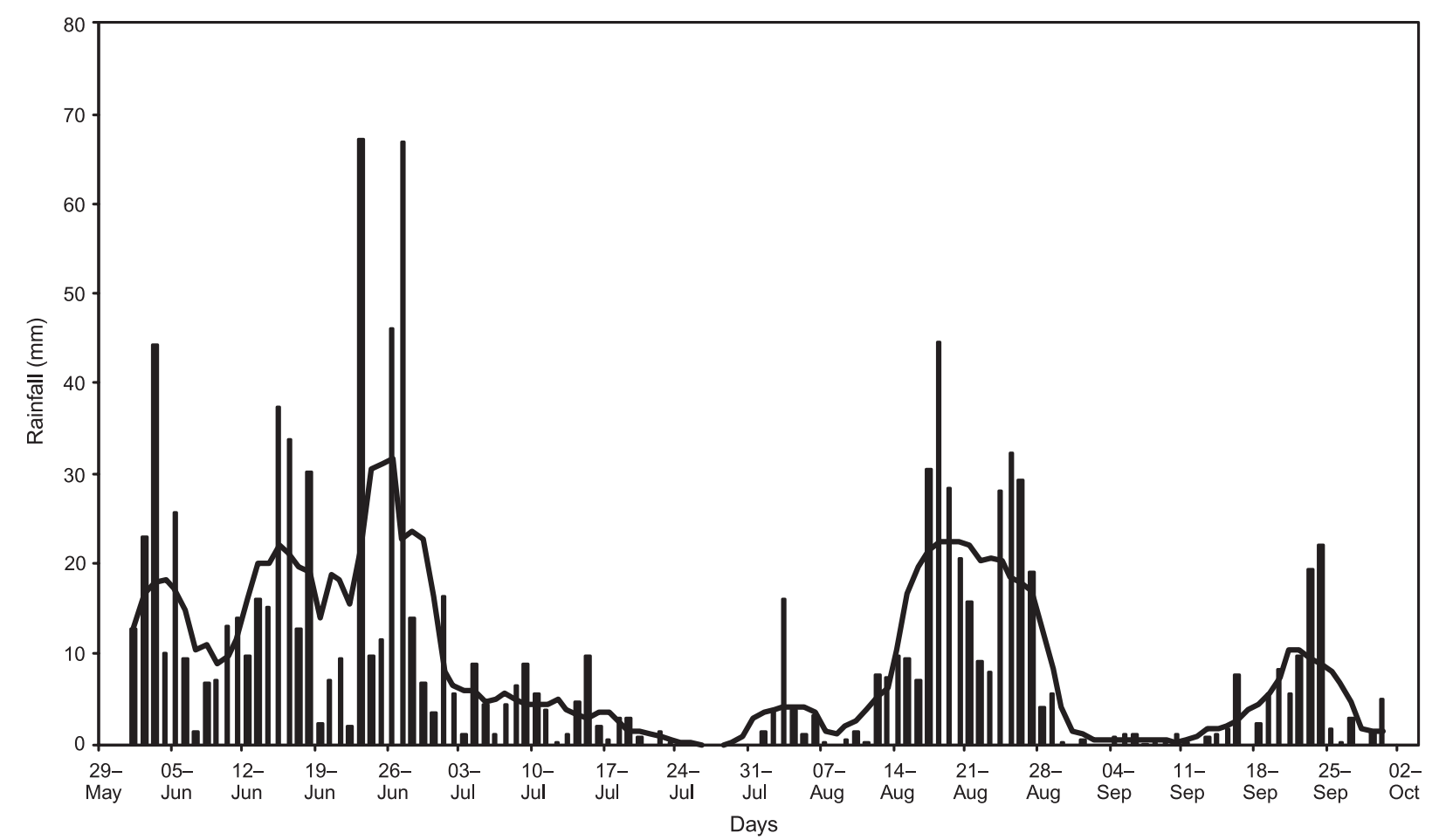

(a)

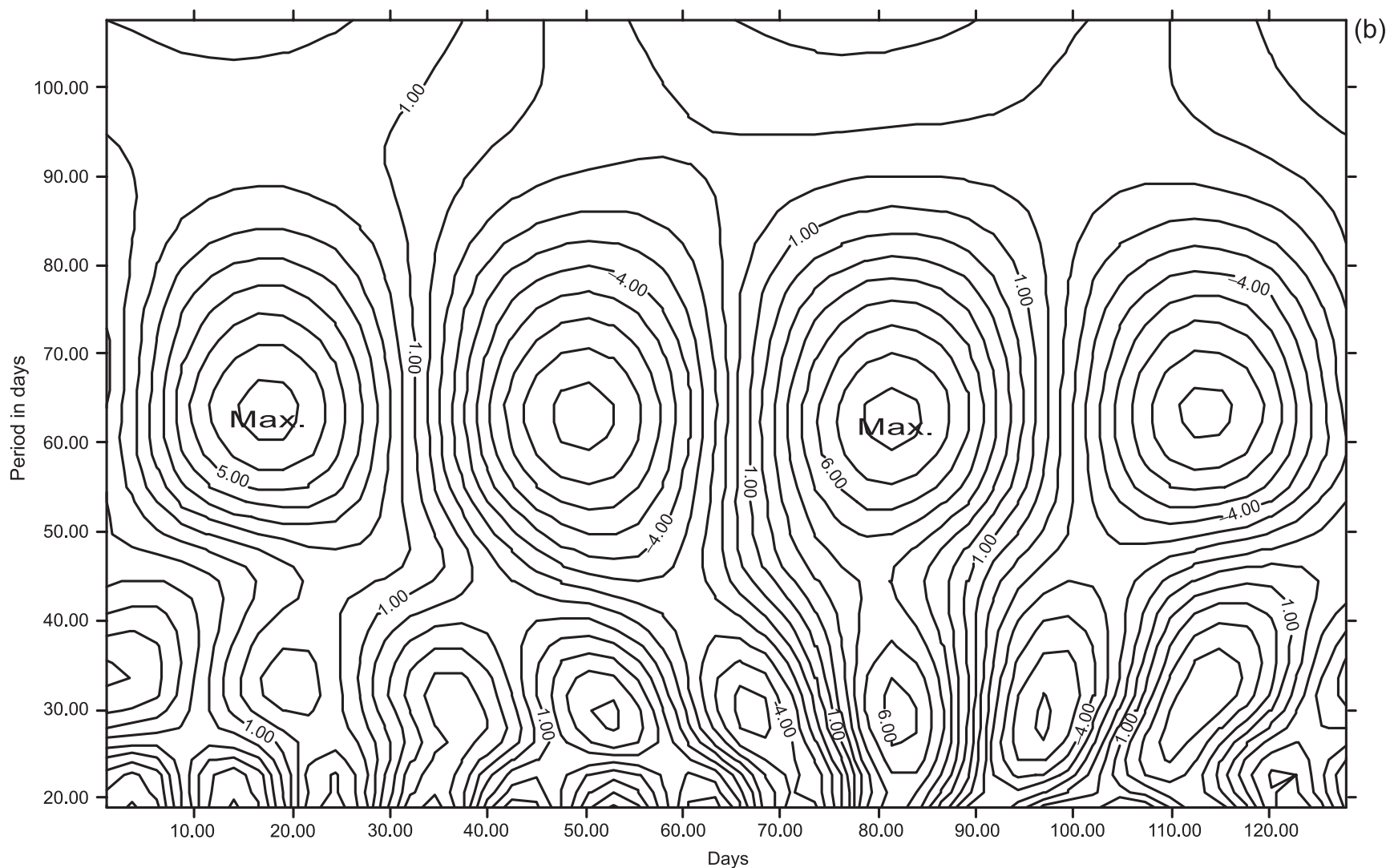

Figure 3. (a) Daily averaged rainfall in mm of south Kerala for 29th May to 3rd October 1987 are shown by the bars and their seven-day moving average by the line graph; (b) Wavelet analysis of south Kerala monsoon rainfall of 1987. Maxima are marked Max. 


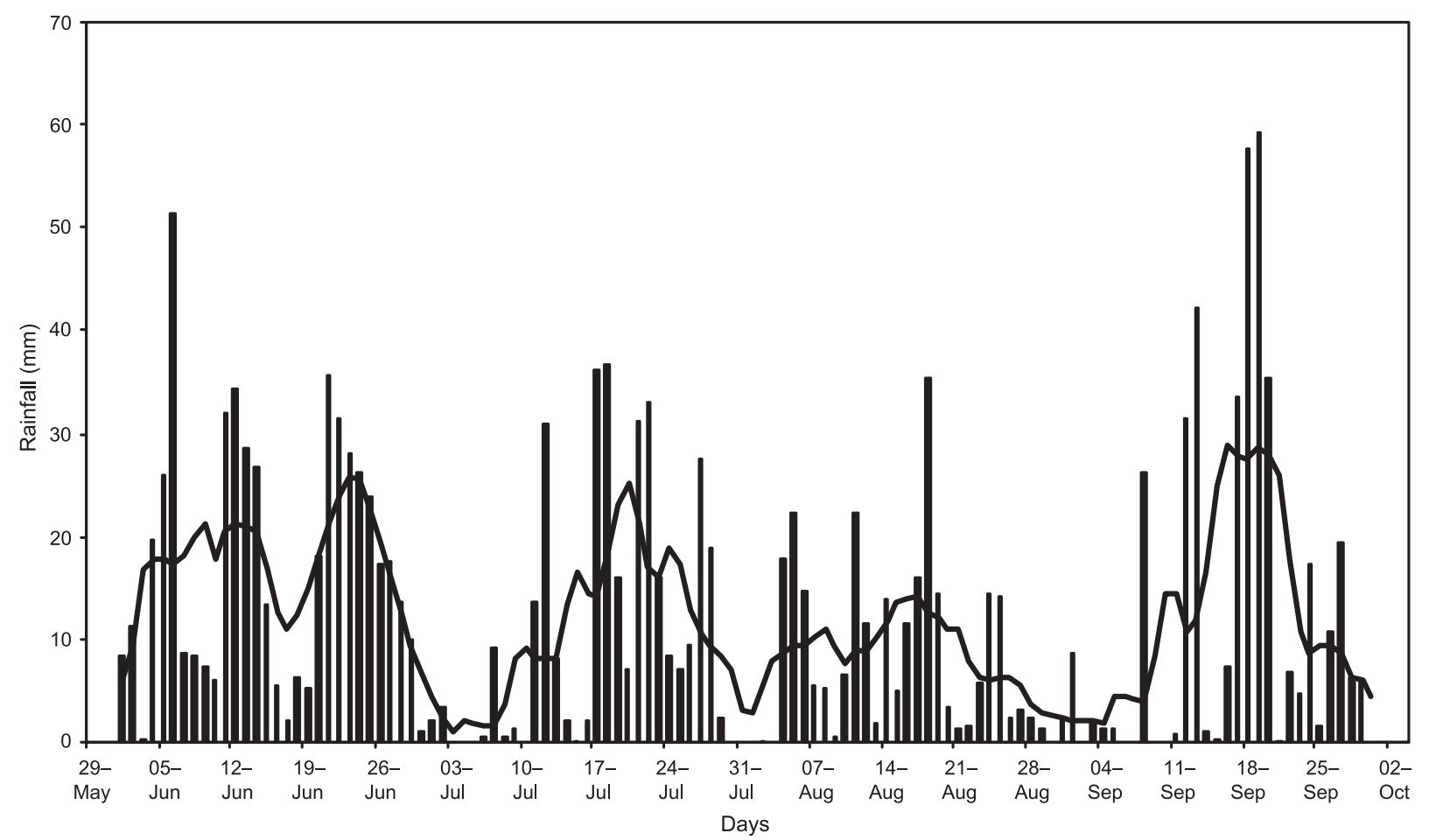

(a)

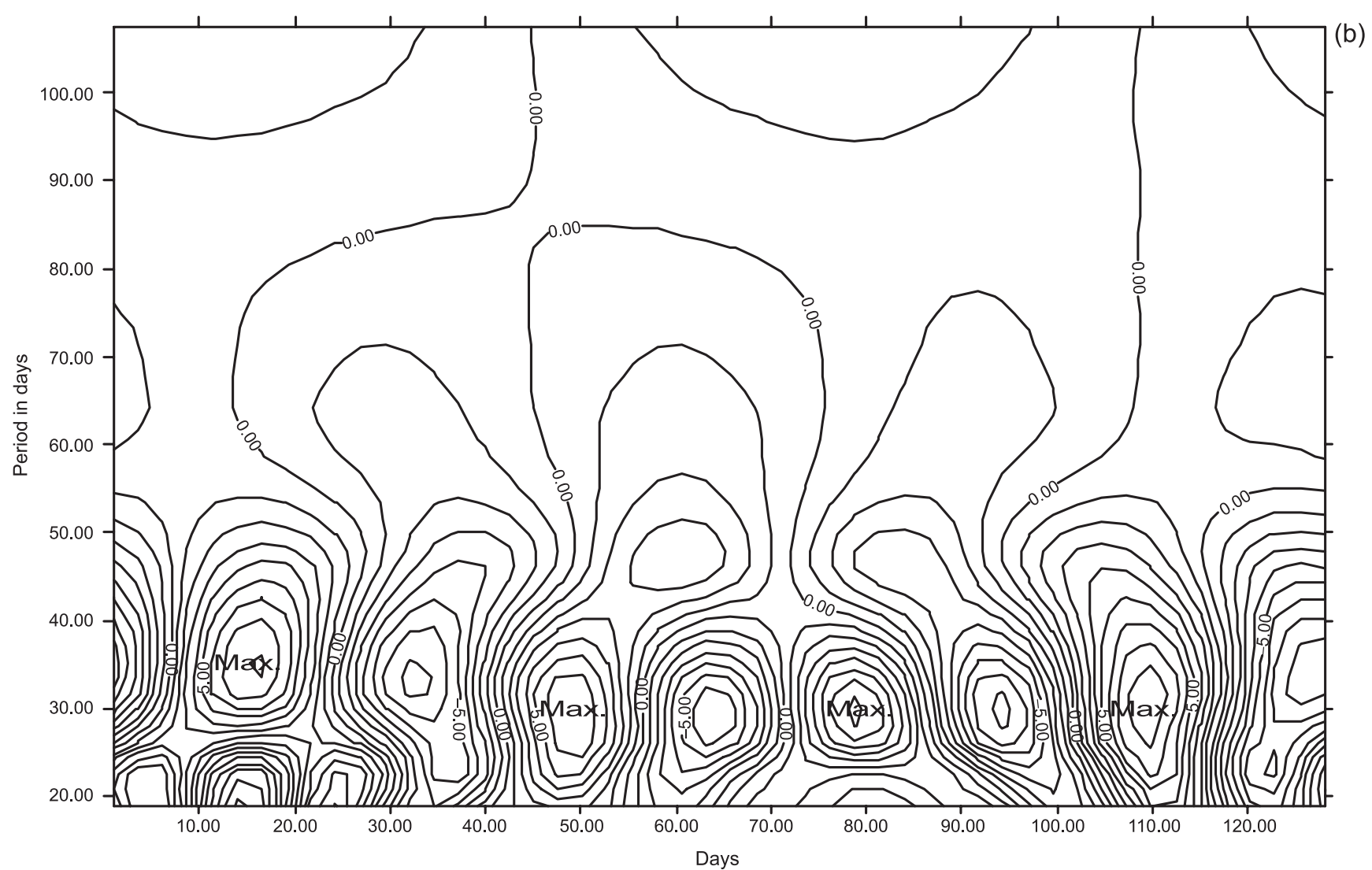

Figure 4. (a) Daily averaged rainfall in mm of south Kerala for 29th May to 3rd October 1989 are shown by the bars and their seven-day moving average by the line graph; (b) Wavelet analysis of south Kerala monsoon rainfall of 1989. Maxima are marked Max. 
ฮ
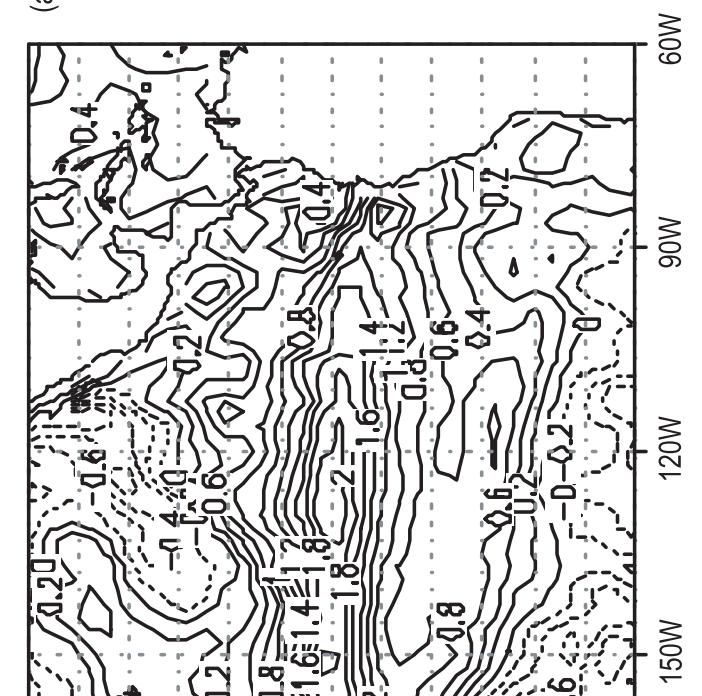

$\therefore$. (7)

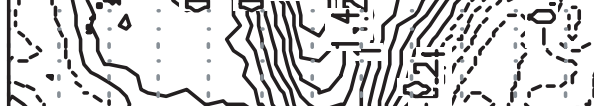

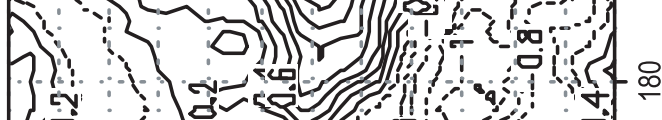

$\int y_{0}$
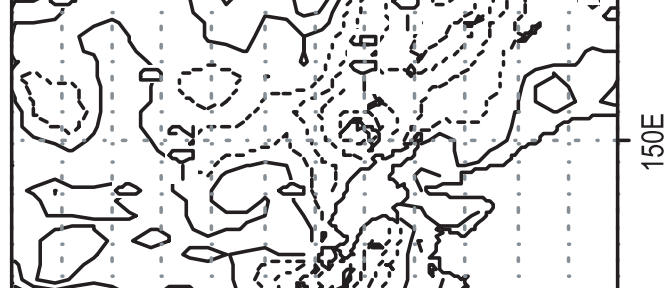

年
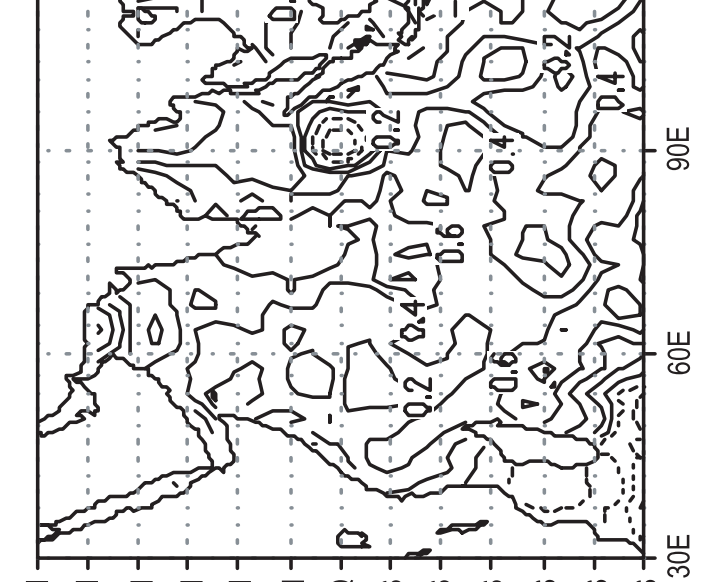

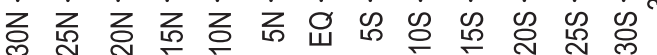

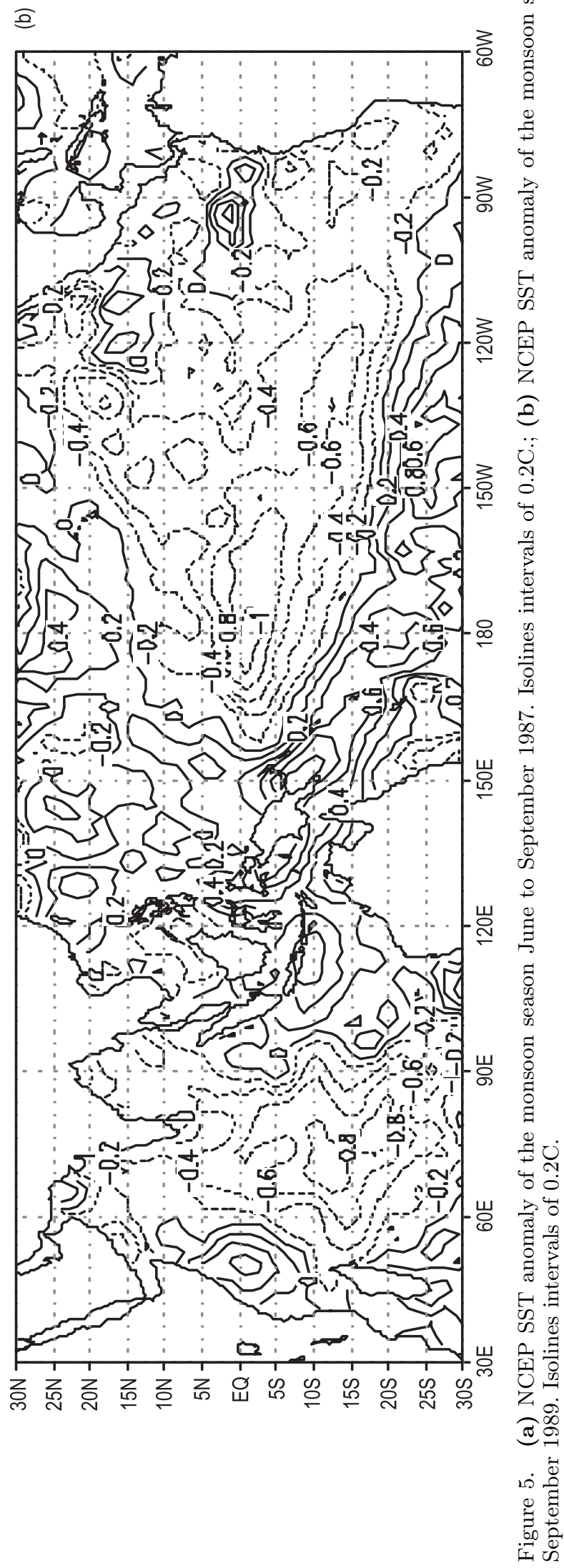




\section{Appendix 1}

Morlet wavelet is defined as the product of a complex exponent wave and a Gaussian envelope:

$$
\varphi_{0}(\eta)=\pi^{-1 / 4} e^{\mathrm{iwo} \eta} e^{-\eta 2 / 3},
$$

where $\varphi_{0}$ is the wavelet value at non-dimensional time $\eta$, and $w_{0}$ is the wave number. The "scaled wavelet" is

$$
\varphi\left[\frac{\left(n^{\prime}-n\right) \delta t}{s}\right]=\left(\frac{\delta t}{s}\right)^{1 / 2} \varphi_{0}\left[\frac{\left(n^{\prime}-n\right) \delta t}{s}\right],
$$

where $s$ is the "dilation" parameter used to change the scale, and $n$ is the translation parameter used to slide in time. The factor of $s^{-1 / 2}$ is a normalization to keep the total energy of the scaled wavelet constant. Details regarding the analysis procedure are given in Torrence and Compo (1998).

For the Morlet wavelet transform, where the mother wavelet is given by (A.1) we first choose the wavenumber $w_{0}$, which gives the number of oscillations within the wavelet itself. One condition of the wavelet transform is that the average of the wavelet itself must be zero. In practice, if we choose $w_{0}=6$, then the errors due to non-zero mean are smaller than the typical computer round-off errors (Farge 1992).

In order to adequately sample all the frequencies present in our time series, we have chosen the smallest resolvable scale, $s_{0}$, which is a multiple of our time resolution, as 2 days. The larger scales (longer periods) are chosen as power-of-two multiples of this smallest scale, and $J$ determines the largest scale.

$$
\begin{aligned}
s_{j} & =s_{0} 2^{j \delta j}, \quad j=0,1, \ldots, J \\
J & =\delta j^{-1} \log _{2}\left(N \partial t / s_{0}\right) .
\end{aligned}
$$

In our analysis we have taken $N=128$ days, $\delta t=1$ day, $s_{0}=2$ days, $\delta j=0.25$ and $J=24$, with periods ranging from 2 days to 107.6 days. The present analysis considers only the period from 20 days to 91 days.

The choice of octave which is logarithmic with the base of 2 as a unit to divide the frequency domain allows us to include a broad range of scales, from very small to very large in an efficient way in a coordinate system with linear interval in octave while logarithmic in frequency scale. In a continuous wavelet transform where more scale decomposition is desired, each octave may be divided further into infinite voices. For this study we have divided each octave into 4 voices.
To determine significance we choose an appropriate background spectrum as follows:

$$
P_{k}=\frac{1-\alpha^{2}}{1+\alpha^{2}-2 \alpha \cos (2 \pi k / N)} K K,
$$

where $k=0 \ldots N / 2$ is the frequency index and $\alpha$ is the lag- 1 autocorrelation.

The null hypothesis is defined for the wavelet power spectrum as follows: It is assumed that the time series has a mean power spectrum, possibly given by (A.3); if a peak in the wavelet power spectrum is significantly above this background spectrum, then it can be assumed to be a true feature with a certain per cent confidence $90 \%, 95 \%$ or $99 \%$.

\section{References}

Ananthakrishnan R and Soman M K 1988 The onset of the southwest monsoon over Kerala: 1901-1980; J. Climatol. $8283-296$

Chowdhury A, Mukhopadhyay R K and Sinha Ray K C 1988 Low frequency oscillations in summer monsoon rainfall over India; Mausam 39 375-382

Farge M 1992 Wavelet transforms and their applications to turbulence; Annu. Rev. Fluid Mech. 24 395-457

Gray B M 1988 Seasonal frequency variations in the 4050 day oscillation; J. Climatol. 8 511-519

Hartmann D L and Michelsen M L 1989 Intraseasonal periodicities in Indian rainfall; J. Atmos. Sci. 46 2838-2862

Joseph P V, Eischeid J K and Pyle R J 1994 Interannual variability of the onset of Indian summer monsoon and its association with atmospheric features, El Nino and sea surface temperature anomalies; J. Climate 7 81-105

Kalnay E et al 1996 The NCEP/NCAR 40-year reanalysis project; Bull. Am. Meteor. Soc. 77 437-471

Krishnamurti T N 1985 Summer monsoon experiment - A review; Mon. Weather Rev. 113 1590-1626

Krishnamurti T N and Subrahmanyam D 1982 The 3050 day mode at $850 \mathrm{mb}$ during MONEX; J. Atmos. Sci. $392088-2095$

Kuhnel I 1989 Spatial and temporal variation in AustraliaIndonesian region cloudiness; Int. J. Climatol. 9 395-405

Lau K M and Chan P H 1985 Aspects of the 40-50 day oscillation during northern winter as inferred from OLR; Mon. Weather Rev. 113 1889-1909

Lau K M and Chan P H 1986 Aspects of the 40-50 day oscillation during northern summer as inferred from OLR; Mon. Weather Rev. 114 1354-1367

Lawrence D M and Webster P J 2001 Interannual variations of the intraseasonal oscillation in the south Asian summer monsoon region; J. Climate 14 2910-2922

Lorenc A C 1984 The evolution of planetary-scale $200 \mathrm{mb}$ divergent flow during the FGGE year; Quart. J. Roy. Meteor. Soc. 110 427-441

Madden R A and Julian P R 1971 Detection of a 40-50 day oscillation in the zonal wind in the tropical Pacific; $J$. Atmos. Sci. 28 702-708

Madden R A and Julian P R 1972 Description of global scale circulation cells in the tropics with a 40-50 day period; J. Atmos. Sci. 29 1109-1123

Madden R A and Julian P R 1994 Observations of the 4050 day tropical oscillation - A Review; Mon. Weather Rev. 122 814-837 
Morlet J 1983 Sampling theory and wave propagation (NATO, ASI Series FI, Springer) 223-261

Murakami T, Chen L X, Xie A and Shreshta 1986 Eastward propagation of 30-60 day perturbations as revealed from outgoing longwave radiation data; J. Atmos. Sci. 42 1107-1122

Rasmusson E M and Carpenter T H 1982 Variations in tropical sea surface temperature and surface wind fields associated with the Southern Oscillation/El Nino; Mon. Weather Rev. 110 354-384

Rui H and Wang B 1990 Development characteristics and dynamic structure of tropical intraseasonal convection anomalies; J. Atmos. Sci. 47 357-379

Sikka D R and Sulochana Gadgil 1980 On the maximum cloud zone and the ITCZ over India longitude during the southwest monsoon; Mon. Weather Rev. 108 1840-1853

Singh S V, Kripalani R H and Sikka D R 1992 Interannual variability of the Madden-Julian oscillations in Indian summer monsoon rainfall; J. Climate 5 973-978

Torrence C and Compo P G 1998 A practical guide to wavelet analysis; Bull. Am. Meteorol. Soc. 79 1 61-78

Tourre Y M and White W B 1995 ENSO signals in global upper ocean temperature; J. Phys. Oceanogr. 25 13171330
Tourre Y M and White W B 1997 Evolution of the ENSO signal over the Indo-Pacific domain; J. Phys. Oceanogr. 683-696

Wang B and Rui 1990 Synoptic climatology of transient tropical intraseasonal convection anomalies, 1975-1985; Meteorol. Atmos. Phys. 44 43-61

Weickmann K M 1983 Intraseasonal circulation and outgoing longwave radiation modes during Northern Hemisphere winter; Mon. Weather Rev. 111 18381858

Weickmann K M, Lussky G R and Kutzbach J E 1985 Intraseasonal (30-60 day) fluctuations of outgoing longwave radiation and $250 \mathrm{mb}$ stream function during northern winter; Mon. Weather Rev. 113 941-961

Yasunari Y 1979 Cloudiness fluctuations associated with the northern hemisphere summer monsoon; J. Met. Soc. Japan. 57 227-242

Yasunari Y 1980 A quasi-stationary appearance of 3040 day period in the cloudiness fluctuations during the summer monsoon over India; J. Met. Soc. Japan 58225 229

Yasunari Y 1981 Structure of an Indian summer monsoon system with around 40-day period; J. Met. Soc. Japan $59336-354$ 